Research Article

\title{
SHPB Testing and Analysis of Bedded Shale under Active Confining Pressure
}

\author{
Guoliang Yang, ${ }^{1,2}$ Jingjiu Bi $\left(\mathbb{D},{ }^{1}\right.$ Xuguang Li $\left(\mathbb{D},{ }^{1}\right.$ Jie Liu, ${ }^{1}$ and Yanjie Feng ${ }^{1}$ \\ ${ }^{1}$ School of Mechanics and Civil Engineering, China University of Mining and Technology, Beijing 100083, China \\ ${ }^{2}$ State Key Laboratory for Geomechanics and Deep Underground Engineering, Beijing 100083, China \\ Correspondence should be addressed to Xuguang Li; artisan_lxg@126.com
}

Received 24 January 2020; Revised 3 April 2020; Accepted 15 April 2020; Published 12 May 2020

Academic Editor: Yuanxin Zhou

Copyright $($ C 2020 Guoliang Yang et al. This is an open access article distributed under the Creative Commons Attribution License, which permits unrestricted use, distribution, and reproduction in any medium, provided the original work is properly cited.

Shale gas is the most important new energy source in the field of energy, and its exploitation is very important. The research on the dynamic mechanical properties of shale is the premise of exploitation. To study the dynamic mechanical properties of shale from the Changning-Weiyuan area of Sichuan Province, China, under confining pressure, we used a split Hopkinson pressure bar (SHPB) test system with an active containment device to carry out dynamic compression tests on shale with different bedding angles. (1) With active confining pressure, the shale experiences a high strain rate, and its stress-strain curve exhibits obvious plastic deformation. (2) For the same impact pressure, the peak stress of shale describes a U-shaped curve with an increasing bedding angle; besides, the peak stress of shale with different bedding angles increases linearly with rising confining pressure. The strain rate shows a significant confining pressure enhancement effect. With active confining pressure, the peak strain gradually decreases as the bedding angle increases. (3) As a result of the influence of different bedding angles, the dynamic elastic modulus of shale has obvious anisotropic characteristics. Shale with different bedding angles exhibits different rates of increase in the dynamic elastic modulus with rising confining pressure, which may be related to differences in the development of planes of weakness in the shale. The results of this study improve our understanding of the behavior of bedded shale under stress.

\section{Introduction}

The purpose of this paper is to provide reference and guidance for shale gas exploration engineering. At present, there are two plans for shale mining: the first is hydraulic fracturing, and the second is blasting mining. In this paper, the dynamic mechanical properties of shale are studied in combination with active confining pressure. Shale gas is an unconventional clean and efficient energy source. Shale-gas reservoir is a bedded sedimentary rock; this bedded structure leads to significant anisotropy in the mechanical properties of the shale. Because the shale-gas reservoir is deeply buried and is affected by the ground stress, it experiences stress from three directions before excavation. That is, it is under the influence of active confining pressure. The rock mass is often affected by mechanical excavation or blasting vibration during the mining process; therefore, dynamic testing of shale with different bedding angles under confining pressure conditions is of great significance for shale-gas exploitation.
The mechanical behavior, strength characteristics, and failure modes of rocks that contain bedding planes exhibit anisotropy. A large amount of previous research has been carried out on bedded rocks. Tien et al. [1] described the failure mechanism and experimental results of the failure process and failure mode of transverse anisotropic rock. Jiang et al. [2], through the uniaxial compression experiment and the establishment of the relevant model, studied the relationship between the generation of microcracks and anisotropy in rock. The results show that the anisotropy is affected by the main direction of microcracks and the direction of maximum stress and that the anisotropy significantly affects the Poisson's ratio of rock. Wasantha et al. [3] studied the mechanical behavior of sandstones in different bedding directions and analyzed the relationship between uniaxial compressive strength and deformation and joint dip in dry and saturated conditions. Peng et al. [4] conducted a Brazilian splitting test and a high-pressure gas fracturing test on black shale combined with high-speed photography and 
acoustic emission systems at different angles. Zhongshan et al. [5] used the acoustic wave test system to study the response of the acoustic characteristics of the shale reservoir to the dip angle of the bedding plane. Zhenkun et al. [6] conducted electron microscopy and uniaxial compression testing on Longmaxi Formation shale with different bedding directions and analyzed and summarized the brittleness anisotropy and corresponding failure modes and laws of shale under different confining pressures for four different bedding angles. Wang et al. [7] put forward a new definition of mechanical brittleness index and a new method to evaluate the brittleness of shale and other brittle rocks by using the crack initiation stress level of the uniaxial stressstrain curve.

There have also been many studies of the mechanical properties of rocks under the confining pressures of deep underground engineering. Xiaocong et al. [8] used the Hopkinson pressure bar equipment with a confining pressure device to test the dynamic mechanical properties of sandstone under different confining pressure levels and different strain rates. Hua et al. [9] used the finite-element software ANSYS/LS-DYNA to establish a numerical model to study the dynamic mechanical properties of concrete under active confining pressure. Chamberlain et al. [10] found, employing a large number of frozen sand triaxial compression experiments, that the plasticity and strength of frozen soil showed a significant confining pressure effect. Fengqiang et al. [11] compared the development and characteristics of different triaxial SHPB rock mechanics testing machines. Using a modified three-axis SHPB dynamic and static combined loading experimental device, the triaxial impact compression process of homogeneous sandstone was studied. Chenglong and Jun [12] studied strain inside the rock and the propagation of surface cracks by active confining pressure constraint and central hole explosion loading tests and used the numerical simulation Johnson-Holmquist model to analyze the failure process of rock material under dynamic and static combined loading. Hua et al. [13] used the LS-DYNA software to simulate an active confining pressure experiment using the concrete Holmquist-Johnson concrete dynamic constitutive model. Zhigang and Shisheng [14] used SHPB test equipment to conduct one-dimensional stress, passive confining pressure, and active confining pressure impact compression experiments and comparative analysis. Junzhong et al. [15-17] conducted impact compression tests on amphibolites, frozen sand, and cement silty clay under different confining pressures and strain rates through active confining SHPB installations. The results showed that brittle rock materials tend to develop ductile characteristics, whereas frozen sands are brittle and are affected by confining pressure and strain rate.

Until now, investigations of the dynamic characteristics of shale have mainly focused on one-dimensional stress tests, and the dynamic mechanical properties of shale under active confining pressure have been less studied. Based on previous research results, this paper simulates the stress state of an underground rock mass. An SHPB test device with active confining pressure was used to exert a load on shale specimens and study their dynamic mechanical response. The results of this study improve our understanding of the behavior of shale under stress, and so will be useful for shalegas exploration in deeply buried rocks.

\section{Test Preparation}

2.1. Sample Preparation. The test samples were obtained from Changning District, Yibin City, Sichuan Province. They are located in the Changning-Weiyuan shale-gas mining area, belonging to Longmaxi Formation of the Silurian system, with a buried depth of about 200-300 m. The shale is dark black with obvious bedding development. The mineral composition is Quartz 39.9\%, K-feldspar 0.5\%, plagioclase $1.1 \%$, calcite $8.9 \%$, dolomite $8.9 \%$, pyrite $2.2 \%$, and total clay mineral $11.8 \%$. To study the influence of different bedding directions on the strength characteristics and mechanical properties of shale, core samples were obtained at different angles such that the bedding planes were at $0^{\circ}, 30^{\circ}, 60^{\circ}$, and $90^{\circ}$ to the direction of coring, as shown in Figure 1. Following the International Society for Rock Mechanics [18], the length-to-diameter ratio of the test piece is $1: 2$, and the rock was processed into a standard test piece of $\Phi 50 \times$ h $25 \mathrm{~mm}$ (Figure 2). The end face and axial nonparallelism of the test piece were controlled to within $0.02 \mathrm{~mm}$

The weight of the rock specimen is $127.80 \mathrm{~g}$ and the density is $2.55 \mathrm{~g} / \mathrm{cm}^{3}$. The static compressive strength of $0^{\circ}$ bedding shale is $138.4 \mathrm{MPa}$, and the static tensile strength is $14 \mathrm{MPa}$; the static compressive strength of $30^{\circ}$ bedding shale is $81.09 \mathrm{MPa}$ and the static tensile strength is $8.7 \mathrm{MPa}$; the static compressive strength of $60^{\circ}$ bedding shale is $54.43 \mathrm{MPa}$ and the static tensile strength is $6.49 \mathrm{MPa}$. The static compressive strength of $90^{\circ}$ bedding shale is $88.56 \mathrm{MPa}$, the static tensile strength is $10.37 \mathrm{MPa}$, and the average longitudinal wave velocity is $4971 \mathrm{~m} / \mathrm{s}$.

2.2. Test Equipment and Programs. The testing was carried out at the China University of Mining and Technology (Beijing). The SHPB test system with a $50-\mathrm{mm}$ rod diameter was used to investigate the dynamic compression of shale specimens in combination with the active confining pressure device (Figure 3 ). The confining pressure stress, which has a maximum value of $30 \mathrm{MPa}$, is generated by hydraulic pressure. When the test specimen is subjected to high-speed impact in the confining pressure device, the inner wall of the confining pressure restricts the radial deformation of the test specimen and the test specimen experiences force from three directions. The test was carried out by manually pressurizing to the confining pressure set point and then striking the shale test specimens with different bedding angles. The parameters of the SHPB test system are provided in Table 1 .

SHPB impact compression tests were carried out on shale samples with different bedding angles under different confining pressures but with the same impact pressure $(0.35 \mathrm{MPa})$. Three effective samples were processed for each set of tests. Specific details of the tests are provided in Table 2. 


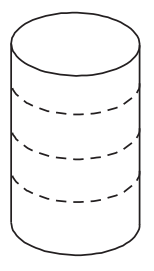

$0^{\circ}$

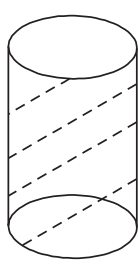

$30^{\circ}$

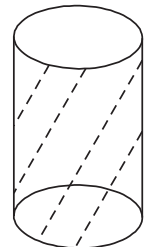

$60^{\circ}$

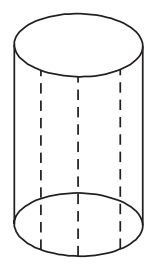

$90^{\circ}$
Figure 1: Directional coring diagram of the sampled shale.

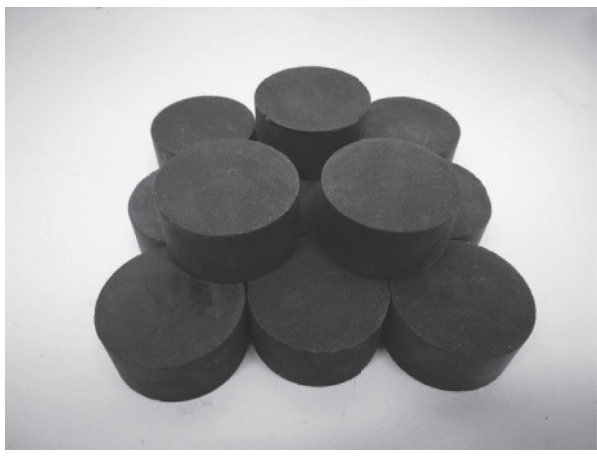

FIgURE 2: Part of prepared rock specimens.

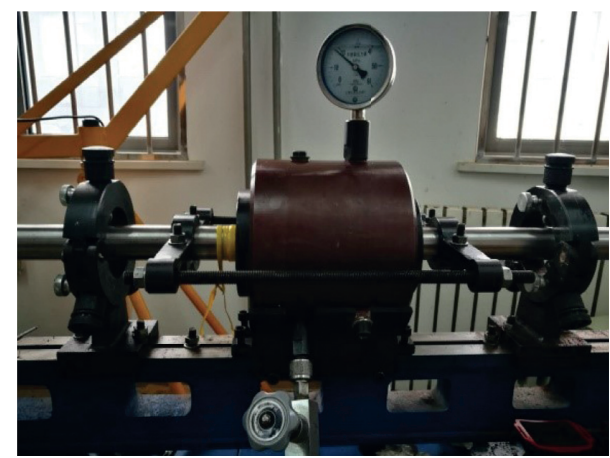

FIGURE 3: The active pressure device installed in the SHPB testing system.

2.3. Experimental Method. To ensure the validity of the data, it is necessary to follow the assumption of one-dimensional stress wave and the assumption of uniformity. The average strain in the specimen is

$$
\varepsilon_{(t)}=\frac{C}{L} \int_{0}^{t}\left[\varepsilon_{i}(t)-\varepsilon_{r}(t)-\varepsilon_{t}(t)\right] \mathrm{d} t
$$

where $C$ is the longitudinal wave velocity of the rod, $L$ is the length of the specimen, and $\varepsilon_{i}(t), \varepsilon_{r}(t)$, and $\varepsilon_{t}(t)$ are the incident wave, reflected wave, and transmitted wave strains, respectively.

The load $F_{i}(t)$ is superimposed on the left end of the sample by an incident wave $\varepsilon_{i}$ and reflected wave $\varepsilon_{r}$. The load $F_{t}(t)$ on the right end of the sample is calculated by the transmitted wave $\varepsilon_{t}$, as shown in Figure 4. These loads are given by

$$
\begin{aligned}
& F_{i}(t)=A E\left[\varepsilon_{i}(t)+\varepsilon_{r}(t)\right], \\
& F_{t}(t)=A E \varepsilon_{t}(t) .
\end{aligned}
$$

The average stress in the specimen is

$$
\sigma(t)=\frac{\left(F_{i}(t)+F_{t}(t)\right)}{2 A_{0}}=\frac{A}{2 A_{0}} E\left[\varepsilon_{i}(t)+\varepsilon_{r}(t)+\varepsilon_{t}(t)\right],
$$

where $A$ and $E$ are the cross-sectional area and elastic modulus of the rod, respectively, and are the cross-sectional area of the specimen.

In the process of dynamic impact, the realization of dynamic force balance is the basis of later analysis and calculation, to ensure the reliability of test results. Figure 5 is a typical dynamic force balance diagram of bedding shale. As shown in Figure 5, the net load (In.+ Re.) applied by the incident wave (In.) and the reflected wave (Re.) on the sample at the incident end is basically the same as the load (Tr.) applied by the transmission wave on the right end of the sample. In the course of the experiment, the parts are basically in the state of dynamic force balance.

\section{Test Results and Analysis}

The results of SHPB impact tests on shale samples with different bedding angles under different active confining pressure conditions are provided in Table 3 . The values in the table are mean values.

\subsection{Influence of Confining Pressure on the Stress-Strain Curve.} The stress-strain curves of shale with different bedding angles were obtained from impact tests under the same loading pressure but different active confining pressure conditions. The stress-strain curves are shown in Figure 6.

With active confining pressure, the dynamic stress-strain curves of the four bedding angles are the same: all undergo an elastic phase, plastic phase, and failure phase. In contrast, the stress-strain curve for the situation without confining pressure does not show obvious brittle failure after peak stress and strain but instead exhibits a brittle-ductile transition. The extension of the plastic phase is a significant feature of the active confining pressure state. This difference may be because the three-directional force under confining pressure causes the shale to be subjected to the maximum principal stress regardless of bedding angle, and mutual displacement of weak bedding planes and penetration by microfractures are limited.

With active confining pressure, the shale experiences a high strain rate, the peak stress and peak strain are significantly increased, and the shale exhibits typical impact strengthening and confining pressure enhancement. When a rock mass deep underground is subjected to confining pressure, on the one hand, the failure strength and bearing capacity of the rock is increased, and on the other hand, the failure strain of the rock is increased and the toughness of the rock is enhanced. The comparison of shale crushing state without confining pressure and underactive confining pressure is shown in Figure 7.

The test data were fitted for the same pressure conditions; the fitting results are shown in Figure 8. 
TABle 1: Parameters of the SHPB experimental system.

\begin{tabular}{lcccccc}
\hline $\begin{array}{l}\text { Bar diameter } \\
(\mathrm{mm})\end{array}$ & $\begin{array}{c}\text { Impact bar } \\
\text { length }(\mathrm{mm})\end{array}$ & $\begin{array}{c}\text { Incident bar } \\
\text { length }(\mathrm{mm})\end{array}$ & $\begin{array}{c}\text { Transmission bar } \\
\text { length }(\mathrm{mm})\end{array}$ & $\begin{array}{c}\text { Density } \\
\left(\mathrm{kg} / \mathrm{m}^{3}\right)\end{array}$ & $\begin{array}{c}\text { Elastic modulus } \\
(\mathrm{GPa})\end{array}$ & $\begin{array}{c}\text { Longitudinal wave velocity } \\
(\mathrm{m} / \mathrm{s})\end{array}$ \\
\hline 50 & 400 & 2000 & 1800 & 7800 & 210 & 5100 \\
\hline
\end{tabular}

TABLE 2: Settings for the SHPB testing of shale.

\begin{tabular}{lcr}
\hline Sample & Confining pressure $(\mathrm{MPa})$ & Bedding angle $\left(^{\circ}\right)$ \\
\hline \multirow{3}{*}{ Shale } & 0 & $0^{\circ}, 30^{\circ}, 60^{\circ}, 90^{\circ}$ \\
& 15 & $0^{\circ}, 30^{\circ}, 60^{\circ}, 90^{\circ}$ \\
& 25 & $0^{\circ}, 30^{\circ}, 60^{\circ}, 90^{\circ}$ \\
\hline
\end{tabular}

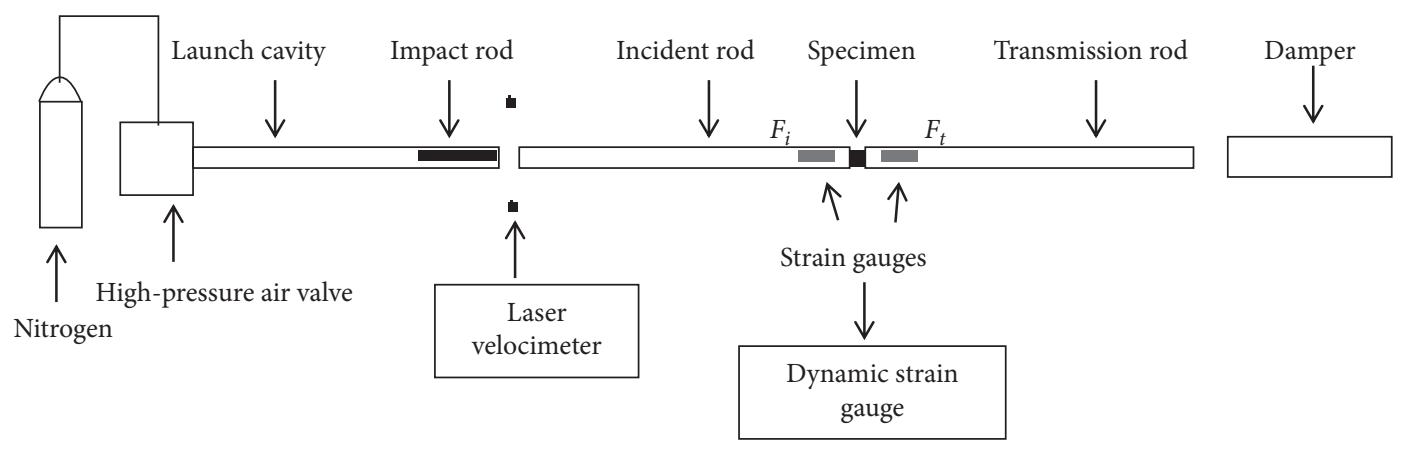

FIGURE 4: Loading schematic of split Hopkinson pressure bar (SHPB) setup.

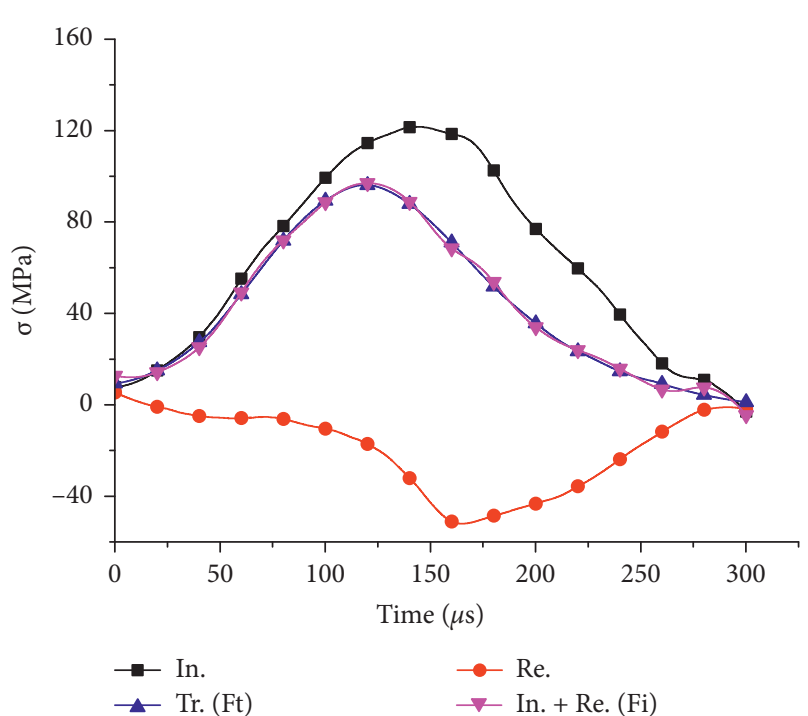

FIGURE 5: Dynamic force balance (In.: incident wave; Re.: reflected wave; Tr.: transmitted wave).

The peak strength of shale with different bedding angles will increase linearly with increasing active confining pressure. The fitting formula is

$$
\sigma_{p}=a p+\sigma_{p 0}
$$

where $\sigma_{p}$ is the peak strength of the shale $(\mathrm{MPa}) ; P$ is the active confining pressure (MPa); $\sigma_{p 0}$ is the average peak strength $(\mathrm{MPa})$ of the shale without confining pressure; $a$ is a parameter related to the fitting. The values of $a, \sigma_{p 0}$, and the correlation coefficient $R^{2}$ under different active confining pressure conditions are listed in Table 4.

The fitting coefficient $a$ reflects the influence of the active confining pressure on the dynamic compressive strength of shale. The effect of active confining pressure on the peak strength of the $90^{\circ}$ bedding shale is significantly less than the effect for other bedding angles. This result may be caused by the weak bedding plane and the direction of the maximum principal stress being parallel under the three-directional stress condition, thereby weakening the ability of the shale to resist impact loads under conditions of active confining pressure. In general, $\sigma_{p 0}$ initially decreases and then increases with rising confining pressure, and the magnitudes of the decrease and increase are approximately the same.

\subsection{Influence of Confining Pressure on Peak Stress and Strain} Rate. The peak stress curves of shale with different bedding angles under different confining pressures were plotted from the data provided in Table 3 and are shown in Figure 9.

When confining pressure is not applied, the curve of peak stress intensity against the bedding angle is U-shaped, with the largest peak stress value $(166 \mathrm{MPa})$ at $0^{\circ}$ and the smallest at $30^{\circ}(143 \mathrm{MPa})$. After applying confining pressure, the peak stress intensity is greatly increased compared to that without confining pressure. Under a confining pressure of $15 \mathrm{MPa}$, the peak stress intensity increases by $17.6 \%$ (at bedding angle $0^{\circ}$ ), 29.7\% (at bedding angle $30^{\circ}$ ), 25.6\% (at bedding angle $60^{\circ}$ ) and $16.7 \%$ (at bedding angle $90^{\circ}$ ) relative 
TABle 3: Test results for shale with different bedding angles under different active confining pressures.

\begin{tabular}{|c|c|c|c|c|c|}
\hline Bedding angle $\left({ }^{\circ}\right)$ & Confining pressure $(\mathrm{MPa})$ & Strain rate $\left(\mathrm{s}^{-1}\right)$ & Peak stress $(\mathrm{MPa})$ & Dynamic elastic modulus (GPa) & Peak strain $\left(10^{-1}\right)$ \\
\hline \multirow{3}{*}{0} & 0 & 193.3 & 166 & 41.5 & 0.0714 \\
\hline & 15 & 447.1 & 195.2 & 41.9 & 0.1710 \\
\hline & 25 & 487 & 227 & 42.4 & 0.2208 \\
\hline \multirow{3}{*}{30} & 0 & 129.6 & 143 & 23.4 & 0.0800 \\
\hline & 15 & 404.6 & 185.5 & 24.3 & 0.1528 \\
\hline & 25 & 418.8 & 199.6 & 25.4 & 0.1820 \\
\hline \multirow{3}{*}{60} & 0 & 162.3 & 144 & 36.6 & 0.0720 \\
\hline & 15 & 443 & 180.8 & 37.5 & 0.1058 \\
\hline & 25 & 475.3 & 209.7 & 38.8 & 0.1178 \\
\hline \multirow{3}{*}{90} & 0 & 192.4 & 165 & 36.4 & 0.0870 \\
\hline & 15 & 451.4 & 192.5 & 40.5 & 0.0933 \\
\hline & 25 & 474.7 & 220.2 & 41.8 & 0.1051 \\
\hline
\end{tabular}

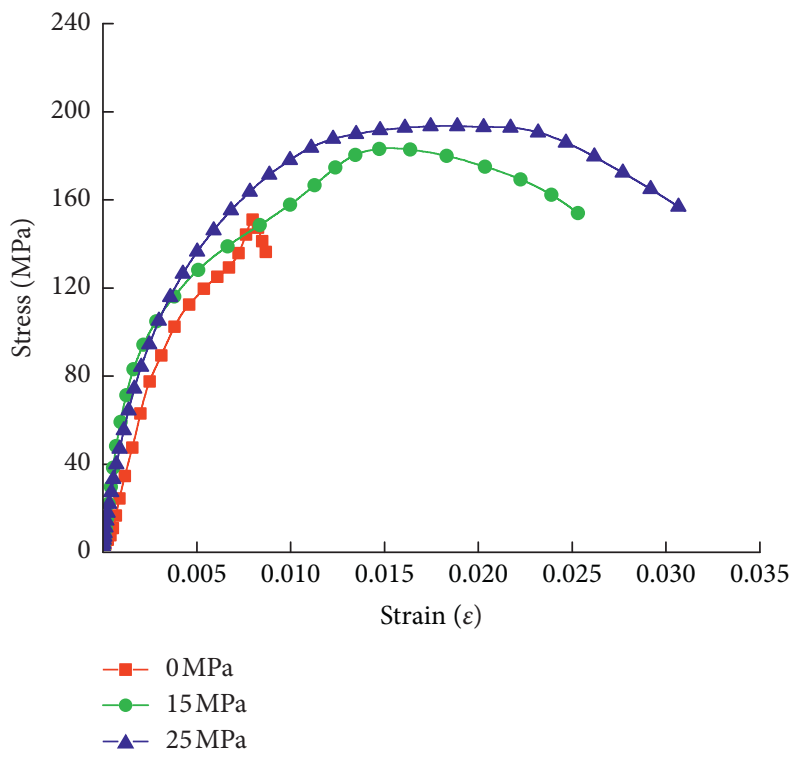

(a)

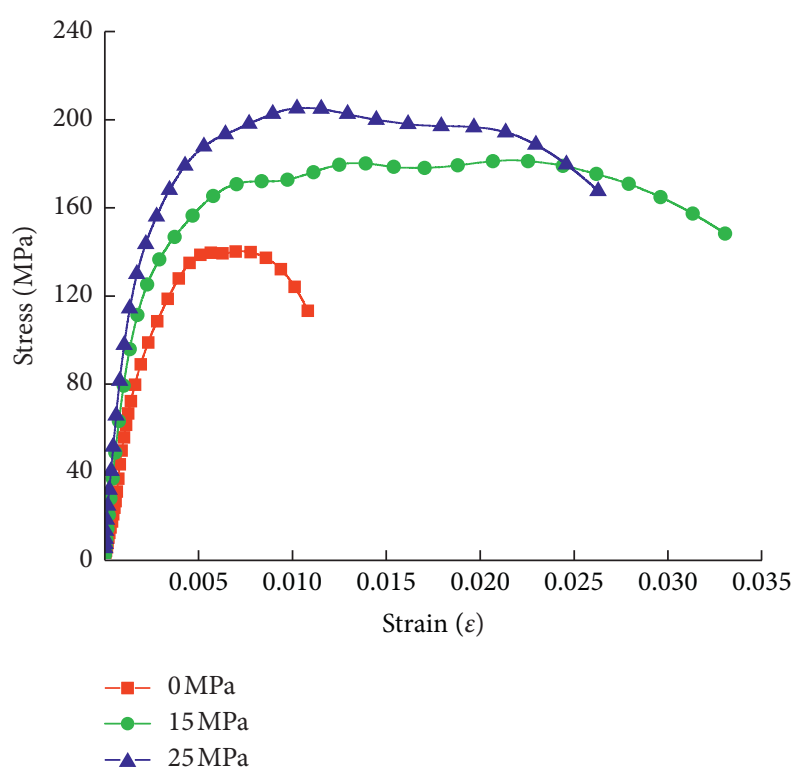

(c)

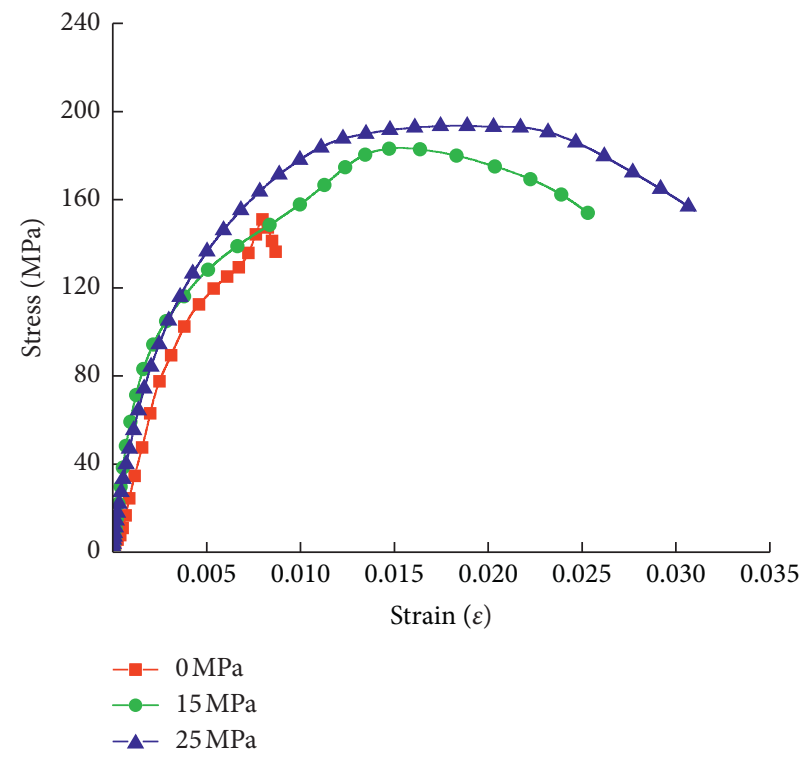

(b)

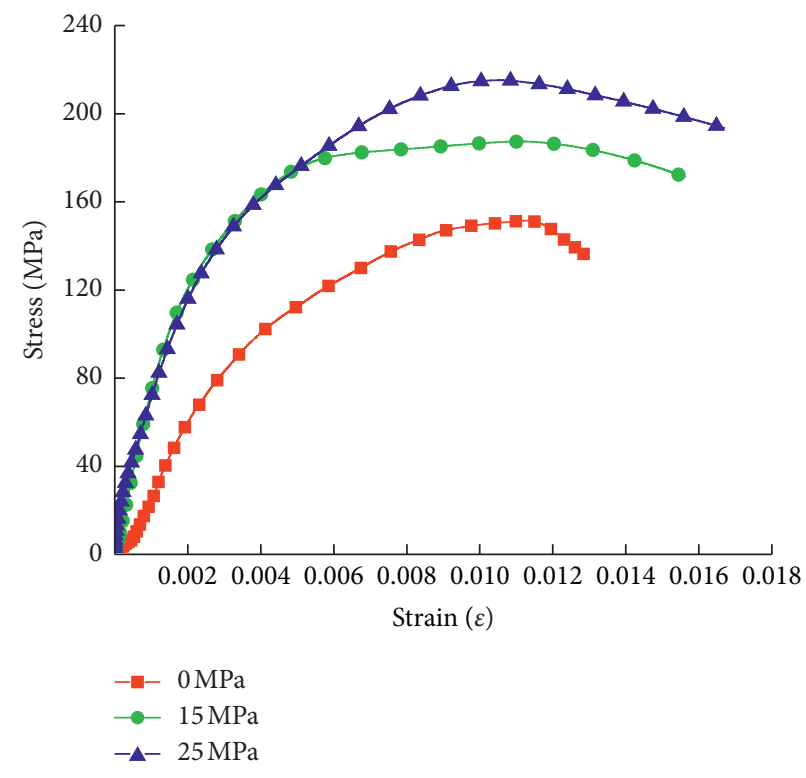

(d)

FIGURE 6: Shale stress-strain curve with different bedding angles. (a) $0^{\circ}$ stress-strain curve. (b) $30^{\circ}$ stress-strain curve. (c) $60^{\circ}$ stress-strain curve. (d) $90^{\circ}$ stress-strain curve. 


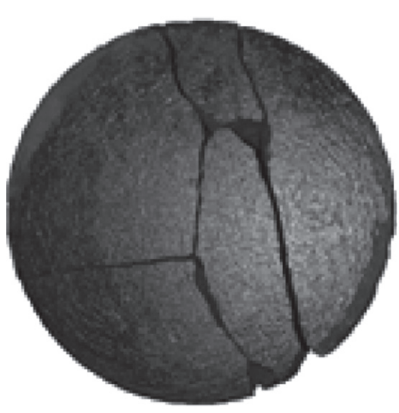

(a)

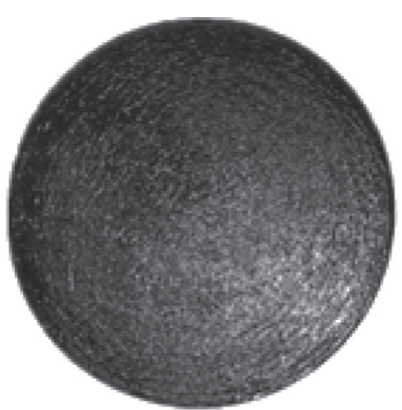

(b)

FIgURE 7: Comparison diagram of specimen crushing.

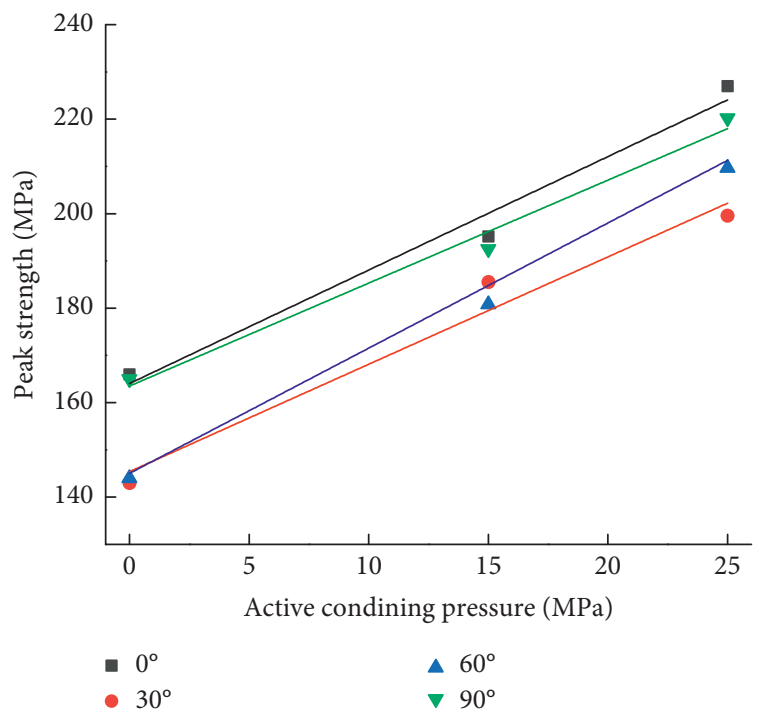

FIgURE 8: Relationships between the active confining pressure and the peak strength of shale for different bedding angles.

TABLE 4: Fitting parameters of $a, \sigma_{p 0}$, and $R^{2}$.

\begin{tabular}{lccc}
\hline Bedding angle & $a$ & $\sigma_{p 0}(\mathrm{MPa})$ & $R^{2}$ \\
\hline $0^{\circ}$ & 2.40 & 164.05 & 0.981 \\
$30^{\circ}$ & 2.30 & 145.24 & 0.972 \\
$60^{\circ}$ & 2.51 & 143.31 & 0.948 \\
$90^{\circ}$ & 2.17 & 163.52 & 0.986 \\
\hline
\end{tabular}

to the nonconfined state. With a confining pressure of $25 \mathrm{MPa}$, the peak stress intensity increases by $36.7 \%$ (at bedding angle $0^{\circ}$ ), 39.6\% (at bedding angle $30^{\circ}$ ), $45.6 \%$ (at bedding angle $60^{\circ}$ ), and $33.5 \%$ (at bedding angle $90^{\circ}$ ) relative to the nonconfined state. This difference is because the shale experiences stress from three directions under confining pressure. The presence of different bedding angles means that the relative slip of the bedding planes and the expansion of internal fissures are suppressed. The dynamic compressive strength of the shale shows anisotropic characteristics.

The strain rate of shale with different bedding angles is greatly increased in the presence of confining pressure compared to the nonconfined state (Figure 10). Under a confining pressure of $15 \mathrm{MPa}$, the strain rate increases by

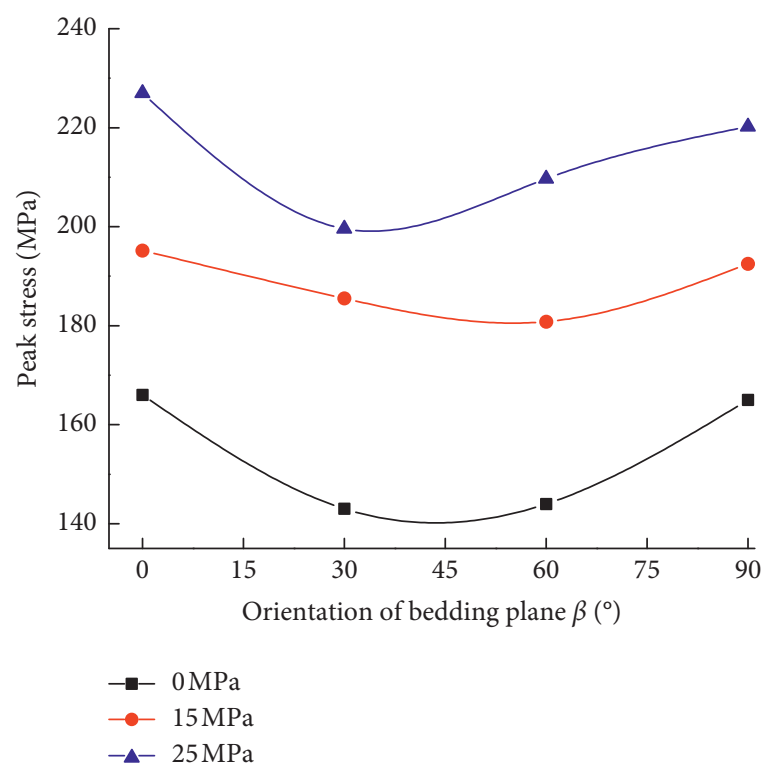

FIGURE 9: Variation of peak stress with bedding plane orientation.

$131.3 \%$ (at bedding angle $0^{\circ}$ ), 212.2\% (at bedding angle $30^{\circ}$ ), $173 \%$ (at bedding angle $60^{\circ}$ ), and $134.6 \%$ (at bedding angle $90^{\circ}$ ) relative to the nonconfined state. Under a confining pressure of $25 \mathrm{MPa}$, the strain rate increases by $151.9 \%$ (at bedding angle $0^{\circ}$ ), 223.1\% (at bedding angle $30^{\circ}$ ), $192.9 \%$ (at bedding angle $60^{\circ}$ ), and $146.7 \%$ (at bedding angle $90^{\circ}$ ) relative to the nonconfined state. These results demonstrate that the strain rate exhibits a significant confining-pressure enhancement effect.

3.3. Influence of Confining Pressure on Peak Strain. The peak strain variation curves of shale with different bedding angles under different confining pressures were plotted from the data provided in Table 3 and are shown in Figure 11.

Peak strain is an important indicator for measuring the deformation characteristics of rock and can be applied to characterize the deformation ability of rock under ultimate loading. The peak strain curve of shale with different bedding angles is almost a straight line when no confining pressure is applied, with no significant changes at different bedding angles (Figure 11). The peak strain of shale under confining 


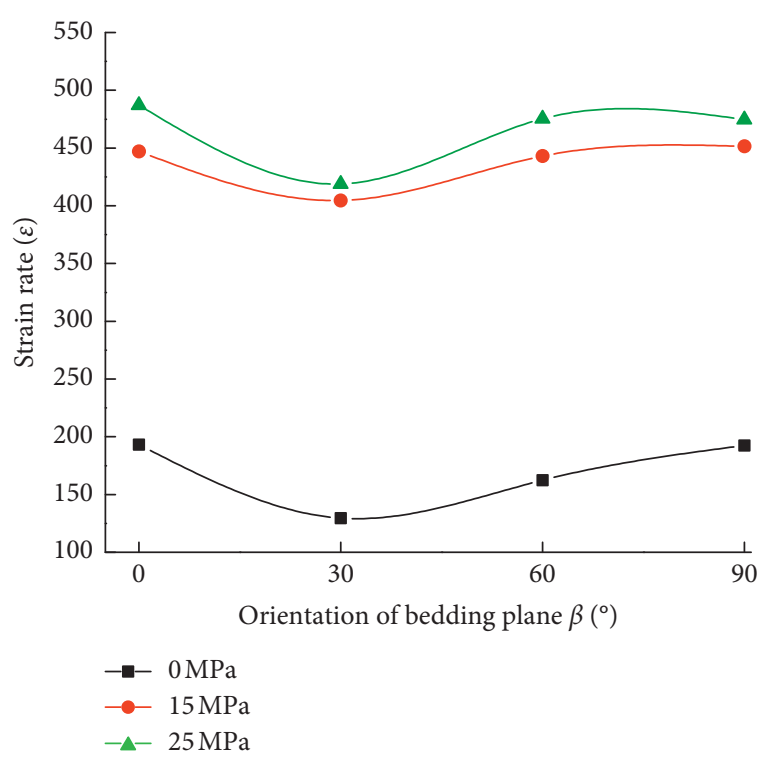

FIGURE 10: Variation of strain rate with bedding plane orientation.

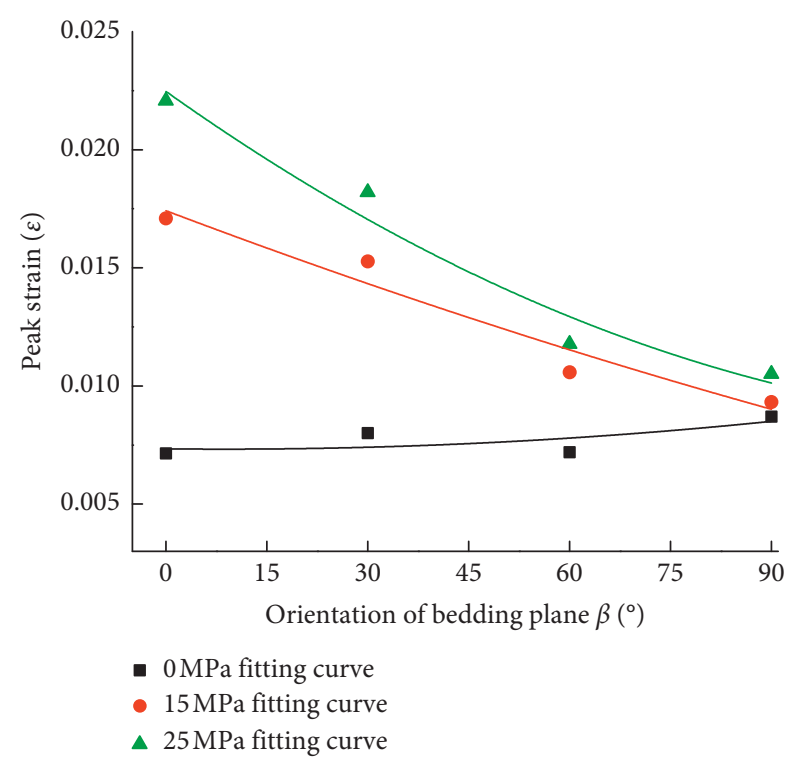

FIGURE 11: Variation of peak strain with bedding plane orientation.

pressure decreases with an increasing bedding angle, and the curve can be divided into two stages. Initially, as the bedding angle is increased from $0^{\circ}$ to $60^{\circ}$, the peak strain decreases rapidly. The peak strain under confining pressures of 15 and $25 \mathrm{MPa}$ decreases from 0.0171 (at bedding angle $0^{\circ}$ ) and 0.02208 (at bedding angle $60^{\circ}$ ) to 0.01058 (at bedding angle $0^{\circ}$ ) and 0.01178 (at bedding angle $60^{\circ}$ ), representing decreases of $38.1 \%$ and $46.6 \%$, respectively. Subsequently, when the bedding angle is increased from $60^{\circ}$ to $90^{\circ}$, the peak strain decreases slowly. The peak strains at confining pressures of 15 and $25 \mathrm{MPa}$ decrease from 0.01058 (at bedding angle $60^{\circ}$ ) and 0.01178 (at bedding angle $90^{\circ}$ ) to 0.00933 (at bedding angle $60^{\circ}$ ) and 0.01051 (at bedding angle $90^{\circ}$ ), representing falls of only $11.8 \%$ and $10.8 \%$, respectively. Based on this test data, the peak strain $\varepsilon$ of shale at $15 \mathrm{MPa}$ and $25 \mathrm{MPa}$ is expressed as a function of the bedding angle $\beta$ :

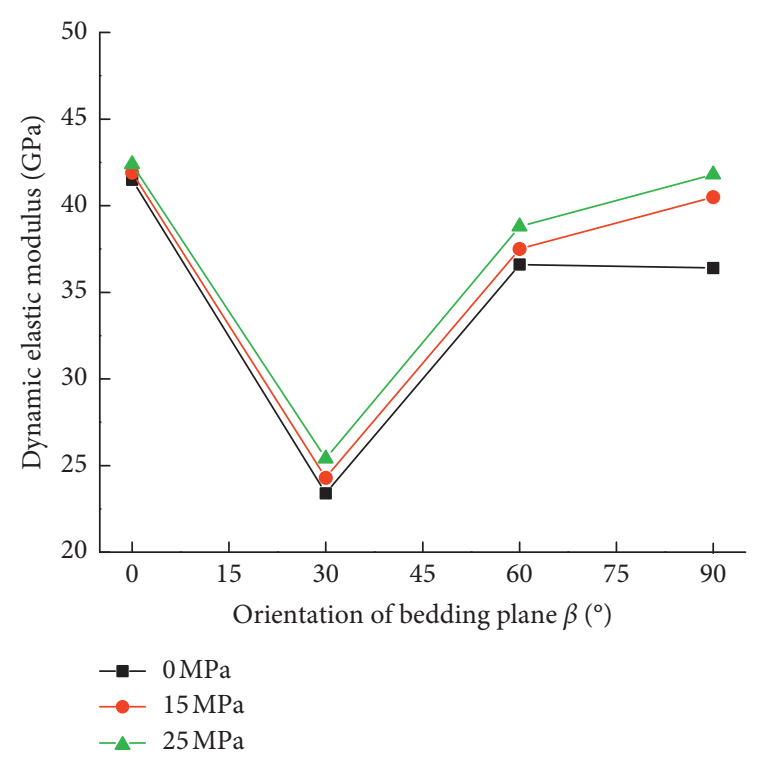

FIgURe 12: Variation of dynamic elastic modulus with bedding plane orientation.

$$
\begin{array}{ll}
\varepsilon=1.583 e^{-7} \beta^{2}-1.076 e^{-4} \beta+0.01742, & R^{2}=0.95151, \\
\varepsilon=7.25 e^{-7} \beta^{2}-2.0235 e^{-4} \beta+0.02246, & R^{2}=0.96687 .
\end{array}
$$

3.4. Influence of Confining Pressure on the Dynamic Elastic Modulus. The values of the dynamic elastic modulus of shale under different confining pressures were plotted from the data provided in Table 3 and are illustrated in Figure 12.

With no confining pressure, as the bedding angle increases, the dynamic elastic modulus initially decreases, then increases, and then slowly decreases, with the largest value at $0^{\circ}$ and the smallest at $30^{\circ}$. With active confining pressure, as the bedding angle increases, the changes in the dynamic elastic modulus follow the same trend as with no confining pressure, although there are some fluctuations in the value.

The change in dynamic elastic modulus with increasing confining pressure is greatest for a bedding angle of $90^{\circ}$. It may be that the application of confining pressure exerts a compacting effect on the weak bedding surfaces and microcracks inside the rock, thereby suppressing lateral deformation of the rock. For the $0^{\circ}$ bedding shale, the bedding weak surface and microcracks are less affected by the confining pressure, and the lateral deformation of the rock is not obvious, so the dynamic elastic modulus is almost unchanged.

\section{Conclusions}

(1) With active confining pressure, the shale experiences a high strain rate. In this situation, the stress-strain curve exhibits greater plastic deformation than in the absence of confining pressure. 
(2) For the same impact pressure, the curve of the peak stress against the bedding angle is U-shaped; besides, the peak stress of shale with different bedding angles increases linearly with increasing confining pressure. The strain rate shows a significant confining pressure enhancement effect. With active confining pressure, the peak strain decreases as the bedding angle increases, with an inflection point of the curve at a bedding angle of $60^{\circ}$. The peak strain and the bedding angle are reduced by the power function.

(3) As a result of the influence of different bedding angles, the dynamic elastic modulus of shale exhibits obvious anisotropy. The dynamic elastic modulus is largest for a bedding angle of $0^{\circ}$ and smallest for a bedding angle of $30^{\circ}$. Shale with different bedding angles displays different rates of dynamic elastic modulus increase with rises in confining pressure, which may be related to differential development of planes of weakness in the shale.

The main innovation of this paper is to combine the bedding shale and the active confining pressure device, which is of great significance, to simulate the real occurrence environment of shale. The research results show that compared with other bedding rocks, the bedding shale has greater strength and more extensive anisotropy, which is more obvious under the condition of active confining pressure. This is of guiding significance for practical engineering.

\section{Data Availability}

The data used to support the findings of this study are available from the corresponding author upon request.

\section{Conflicts of Interest}

The authors declare that they have no conflicts of interest.

\section{Acknowledgments}

The authors acknowledge the support from the opening project of State Key Laboratory of Explosion Science and Technology (Beijing Institute of Technology) (opening project number: KFJJ19-10M).

\section{References}

[1] Y. M. Tien, M. C. Kuoa, and C. H. Juang, “An experimental investigation of the failure mechanism of simulated transversely isotropic rocks," International Journal of Rock Mechanics and Mining Sciences, no. 43, pp. 1163-1181, 2006.

[2] M. Jiang, R. Guan, J. Peng et al., "Dominant micro-cracking direction and anisotropic property of rocks under uniaxial compression," Environmental Earth Sciences Volume, vol. 77, p. 346, 2018.

[3] P. L. P. Wasantha, P. G. Ranjith, and S. S. Shao, "Energy monitoring and analysis during deformation of beddedsandstone: use of acoustic emission," Ultrasonics, no. 54, pp. 217-226, 2014.
[4] H Peng, G. Feng, Y. Yugui et al., "Effect of bedding plane direction on acoustic emission characteristics of shale in Brazilian tests," Rock and Soil Mechanics, vol. 37, no. 6, pp. 1603-1612, 2016, in Chinese.

[5] L. Zhongshan, C. Han, S. Pinghe et al., "Experimental study on acoustic and mechanical response of anisotropy in shale reservoirs in northwest-ern Hunan," Coal Science Technology Magazine, vol. 3, pp. 1-4, 2018, in Chinese.

[6] H. Zhenkun, Y. Chunhe, G. Yintong et al., "Experimental study on anisotropic properties of Longmaxi formation shale under uniaxial compression," Rock and Soil Mechanics, vol. 36, no. 9, pp. 2541-2550, 2015, in Chinese.

[7] Y. Wang, C. Li, Y. Hu et al., "A new method to evaluate the brittleness for brittle rock using crack initiation stress level from uniaxial stress-strainn curves," Environmental Earth Sciences Volume, vol. 76, p. 799, 2017.

[8] L. Xiaocong, X. Jinyu, G. Honghai et al., "Effects of confined pressure on mechanical behaviors of sandstone under dynamic impact loads," Chinese Journal of Rock Mechanics and Engineering, vol. 29, no. 1, pp. 193-201, 2010.

[9] Z. Hua, G. Yuwei, and W. Shoufeng, "Numerical simulation of SHPB test with confining pressure device for concrete," Journal of Hefei University of Technology: Natural Science, vol. 35, no. 2, pp. 216-220, 2012.

[10] E. Chamberlain, C. Groves, and R. Perham, "The mechanical behaviour of frozen earth materials under high pressure triaxial test conditions," Géotechnique, vol. 22, no. 3, pp. 469-483, 1972.

[11] G. Fengqiang, L. Xibing, and L. Xiling, "Tests for sandstone mechanical properties and failure model under triaxial SHPB loading," Journal of Vibration and Shock, vol. 31, no. 8, pp. 29-32, 2012, in Chinese.

[12] H. Chenglong and Y. Jun, "Research on dynamic response of rock under blast loading and active confining pressure," Acta Armamentaril, vol. 38, no. 12, pp. 2395-2405, 2017, in Chinese.

[13] Z. Hua, G. Yuwei, and W. Shoufeng, "Numerical simulation of SHPB test with confining pressure device for concrete," Journal of Hefei University of Technology, vol. 35, no. 2, pp. 216-220, 2012, in Chinese.

[14] X. Zhigang and H. Shisheng, "Dynamic behavior of cement mortar under confinement," Engineering Mechanics, vol. 25, no. 12, pp. 184-201, 2008, in Chinese.

[15] L. Junzhong, X. Jinyu, Z. Dehui et al., "Experimental study of shock compression properties of underground engineering rock under active confining pressure," Chinese Journal of Rock Mechanics and Engineering, vol. 30, no. S2, pp. 4104-4109, 2011, in Chinese.

[16] M. Dongdong, M. Qinyong, Y. Pu et al., "SHPB tests on artificial frozen sand and its analysis under active confining pressure," Rock and Soil Mechanics, vol. 38, no. 10, pp. 2957-2972, 2017, in Chinese.

[17] G. Changhui, M. Qinyong, and M. Dongdong, "SHPB test and analysis on cemented silty clay under confining pressure conditions," Journal of Vibration and Shock, vol. 37, no. 14, pp. 162-167, 2018, in Chinese.

[18] C. E. Fairhurst and J. A. Hudson, "Draft ISRM suggested method for the complete stress-strain curve for intact rock in uniaxial compression," International Journal of Rock Mechanics and Mining Sciences, vol. 36, no. 3, pp. 279-289, 1999. 